\title{
Flipped Teaching y Redes Sociales
}

\section{María-Ángeles Carabal-Montagud ${ }^{\mathrm{a}}$, Virginia Santamarina-Campos ${ }^{\mathrm{b}}$, María-Victoria Esgueva-López ${ }^{\mathrm{c}}$, María de-Miguel-Molina ${ }^{\mathrm{d}}$}

${ }^{a}$ Departamento de Conservación y Restauración de Bienes Culturales, Universitat Politècnica de València, macamon@crbc.upv.es bepartamento de Conservación y Restauración de Bienes Culturales, Universitat Politècnica de València, virsanca@crbc.upv.es ${ }^{\circ}$ Departamento de Dibujo, Universitat Politècnica de València, maeslo2@dib.upv.es y ${ }^{\mathrm{d}}$ Departamento de Organización de Empresas, Universitat Politècnica de València, mademi@omp.upv.es

\begin{abstract}
The "Flipped Teaching" or "Flipped Classroom" can be given from multiple channels. We usually share the information through institutional channels, in fact PoliformaT, within the UPV, is key in any teaching methodology. The present work intends to explore other access ways to information to complement those that we use in a habitual way. Social networks have become protagonists in any type of communication. In this article we present social media from the perspective of their innovative teaching capacity, which adds a playful perception to learning, is attractive to students and favors the acquisition of content with easy access.
\end{abstract}

Keywords: flipped teaching, flipped classroom, training, metodology, innovation, social media

\footnotetext{
Resumen

La "Docencia Inversa", "Flipped Teaching" o "Flipped Classroom" puede darse desde multiples canales. Habitualmente compartimos la información a través de canales institucionales, de hecho PoliformaT, dentro de la UPV, es clave en cualquier metodología docente. El presente trabajo pretende explorar otras vías de acceso a la información para complementar a los que empleamos de modo habitual. Las redes sociales se han convertido en protagonistas en cualquier tipo de comunicación. En el presente artículo presentamos las redes sociales desde la perspectiva de su capacidad docente innovadora, que añade una percepción lúdica al aprendizaje, resulta atractivo al alumnado y favorece la adquisición de contenidos con un fácil acceso.
}

Palabras clave: docencia inversa, flipped teaching, flipped classroom, formación, metodología, innovación, redes sociales 


\section{Introducción}

Las redes sociales son un canal de comunicación común para el alumnado, que les resulta familiar, cómodo, asequible, intuitivo y, sobre todo, lúdico, ya que suelen utilizarlo para comunicarse entre sí. Desde plataformas como WhatsApp, con 1.200 millones de usuarios a nivel mundial y con un 93,4\% de usuarios españoles de mensajería instantánea, según el Centro de Investigaciones Sociológicas (CIS, 2017).

La participación en diferentes redes sociales, como Facebook, Twitter o Instagram, según la misma fuente, asciende al 72,4\% de la población española, con un 93,3\% en la franja de edad de 18 a 24 años, y con un 94,7\% en la franja de 25 a 34 años, con una participación decreciente en franjas de edad superiores (CIS, 2017).

Teniendo en cuenta estos datos, el alumnado de nuestras aulas, salvo alguna excepción, suele estar en estas franjas de edad, con lo que la gran mayoría de los mismos hace uso de las redes sociales a nivel cotidiano.

Ahora bien, las redes sociales son canales que se amoldan a sus necesidades, a sus inquietudes, les resultan intuitivas, rápidas, sencillas y, sin apenas ser conscientes de ello, de manera lúdica, realizan aprendizaje en múltiples aspectos... entonces ¿por qué no utilizarlas para la docencia universitaria?

La presente innovación no se plantea como un canal único o se compara con otras plataformas existentes, sobre todo las institucionales de cada universidad, ya que son el mejor medio para transferir la información. La siguiente innovación se plantea teniendo en cuenta que el alumnado ya realiza un trabajo de docencia inversa a través de PoliformaT en el caso de la UPV- con la lectura previa de apuntes, textos, etc., pero todo ello se puede complementar mediante el uso de las redes sociales.

Según el estudio de Haro "Las redes sociales permiten el uso masivo por parte de miles de alumnos y cientos de profesores [...]. De este modo se favorece la incorporación generalizada de las TIC en los centros educativos, algo que ya se está empezando a producir en algunos de ellos” (Haro, 2009). En la presente investigación se plantea el uso de las mismas para exponer al alumnado las prácticas a efectuar en el laboratorio, empleando estas apps, fundamentalmente Instagram o YouTube para flipped classroom, haciendo uso de imágenes y audiovisuales, que resultan atractivas y se adaptan a su código visual. Se expondrá la experiencia en la asignatura "Técnicas Instrumentales de la Restauración de Dorados y Policromías”, optativa de tercer curso del Grado en Conservación y Restauración de Bienes Culturales, para posteriormente analizar el resultado de su implantación mediante encuestas de opinión del alumnado, además de la valoración de los resultados objetivos de las prácticas.

(cc) EY-NC-ND 2018, Universitat Politècnica de València

Congreso IN-RED (2018) 


\section{Objetivos}

El objetivo principal de la presente innovación se centra en la búsqueda de canales, paralelos a los institucionales, en los que desarrollar la docencia inversa de modo que el alumno realice el aprendizaje con una percepción lúdica.

Los objetivos específicos:

- Implementar apps en la docencia inversa, que faciliten el acceso a la información.

- Generar contenidos en otros medios que sean asequibles y familiares para el alumnado.

- Analizar la respuesta del alumnado mediante las encuestas de opinión con la plataforma SurveyMonkey®.

- Contribuir a un aprendizaje virtual colaborativo, mediante plataformas de ocio.

- Acceder a la realidad empresarial, mediante sus redes sociales, enlazando los contenidos de la asignatura con su futuro laboral.

\section{Desarrollo de la innovación}

\subsection{Justificación}

Como se ha citado con anterioridad, el desarrollo de la innovación se ha llevado a cabo en la asignatura “Técnicas Instrumentales de la Restauración de Dorados y Policromías”, del Grado en Conservación y Restauración de Bienes Culturales.

La mencionada asignatura consta de 6 créditos ECTS en el actual Grado, mientras que en la anterior licenciatura, contaba con 12 créditos presenciales. El tiempo en el aula se ha reducido a la mitad, pero los contenidos deben mantenerse, e incluso ampliarse, independientemente de este cambio. De ahí surge la necesidad de implementar el flipped teaching en la docencia, y más teniendo en cuenta que la práctica ocupa casi la totalidad del tiempo en el laboratorio.

Las prácticas a efectuar suelen estar relacionadas con procesos que deben llevarse a cabo en el aula, dado que es el espacio para trabajar la resolución de problemas ante situaciones complejas que se puedan presentar, y ante la dificultad de alguna de las técnicas a desarrollar. Con ello, el tiempo de la teoría se tiene que ver considerablemente reducida para dar paso a la realidad de la práctica. El flipped teaching ha dado una nueva perspectiva para poder desarrollar esta docencia.

En este punto nos encontramos ante una dualidad, dado que el alumnado presenta alta carga de trabajo fuera del aula, para completar sus créditos ECTS, pero por otro lado tenemos la necesidad de que asimilen ciertos contenidos de modo previo a efectuar la práctica. En ocasiones, el trabajo no presencial, unido a la totalidad de asignaturas que cursa, genera en el alumnado una percepción de falta de tiempo para completar todas las tareas. Una herramienta básica para llevar a cabo la docencia inversa consiste en subir en las plataformas institucionales, como PoliformaT en la UPV, los apuntes, textos, o documentos, bien como archivos adjuntos o bien con la propia herramienta Lessons, que 
permite generar apuntes, incorporando imágenes, texto, vídeos, etc. También la UPV oferta a su profesorado una gran cantidad de posibilidades a la hora de acceder a la información audivisual a modo de screencasts, polimedia, videoapuntes, vídeos didácticos, cursos MOOC, registro de voz, etc. (UPV, 2018).

No obstante, las plataformas públicas que analizaremos en el presente estudio han sido analizadas durante este curso debido a que los jóvenes son la población que mayor uso hace de las diferentes plataformas, o apps, como se ha expuesto con anterioridad, según datos del CIS de noviembre de 2017 (CIS, 2017).

Los dispositivos móviles forman parte de nuestro sistema social actual "Para el alumnado, en el siglo XXI, estar conectado, de manera ininterrumpida, con los estímulos provenientes de las redes sociales, es la realidad a la que nos enfrentamos en las aulas universitarias" (Carabal et al., 2017).

Según Terrasa y Andreu: “Adaptarse al nuevo carácter de nuestros estudiantes implica un cambio en las metodologías docentes utilizadas” (Terrasa, Andreu, 2015). A la hora de escoger las plataformas adecuadas, se ha tenido en cuenta que éstas no tuviesen una finalidad específica, que diesen la posibilidad de versatilidad, ya que "La diversidad de las redes sociales lleva a hacer distinciones entre ellas. Por un lado, encontramos las redes sociales genéricas, cuya temática no está definida, como son Facebook, Twitter, YouTube e Instagram” (Espinosa et al., 2017).

Las plataformas escogidas han sido fundamentalmente Instagram y YouTube en menor medida. El motivo de la selección es debido a que el alumnado, en una encuesta de opinión a través de la plataforma SurveyMonkey®, ha valorado que su preferencia a la hora de conocer las prácticas, previamente a efectuarlas, es mediante el uso de audiovisuales, con un porcentaje del $79,49 \%$. Los textos obtuvieron un $15,38 \%$ de porcentaje y las encuestas un 5,13\%.

\section{¿Qué clase de material me resulta más útil?}

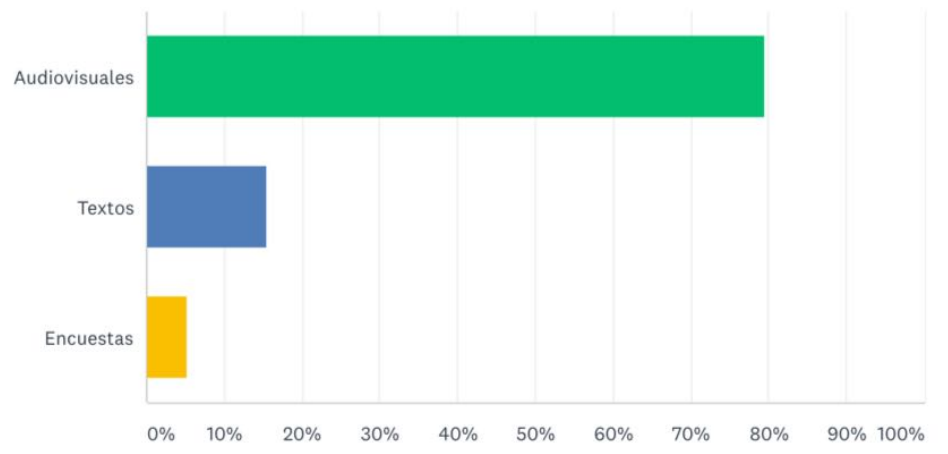

Fig.1. Resultados de la encuesta con la plataforma SurveyMonkey®

(cc) EY-NC-ND 2018, Universitat Politècnica de València

Congreso IN-RED (2018) 
Cabe destacar que el uso de audiovisuales resultan muy útiles en nuestra área, dada la carga informativa que conlleva y la facilidad que otorgan de fijar procesos y contenidos.

Analizaremos la citada encuesta (Carabal, 2018), que ha sido planteada al alumnado para valorar de modo instantáneo sus preferencias u opiniones, mediante una plataforma sencilla e inmediata. En ella se recogen una serie de preguntas relacionadas con el uso de las aplicaciones mencionadas con anterioridad, en los que se valora su percepción al respecto de la utilidad del flipped classroom, de los canales de acceso a la información y de las redes sociales, con sus ventajas y desventajas.

\subsection{Metodología docente}

La metodología llevada a cabo se ha desarrollado en dos sentidos, que han sido:

\subsubsection{Elaborar material y "subirlo" a Instagram o YouTube}

La metodología ha consistido en efectuar imágenes y vídeos, de modo previo a la práctica. Obviamente conlleva trabajo para el profesor, dado que hay que efectuarlo con previsión y conlleva una minuciosa planificación de los tiempos del aula, para que la imagen o el vídeo sea planteado en el momento oportuno. No obstante, las ventajas que presenta son mayores a los inconvenientes, dado que en un amplio porcentaje es visualizado por el alumnado, como puede valorarse en el aula, mediante el planteamiento de dudas y el debate previo a la práctica, en el que la inmensa mayoría ha cumplido el objetivo de la docencia inversa.

Previamente se hace un sondeo anónimo, acerca de la predisposición del alumnado al uso de redes, dado que tampoco se pretende invadir su privacidad. La totalidad del alumnado suele estar de acuerdo con el uso de las mismas, dado el carácter que otorgan estos canales de adaptación a sus necesidades. 


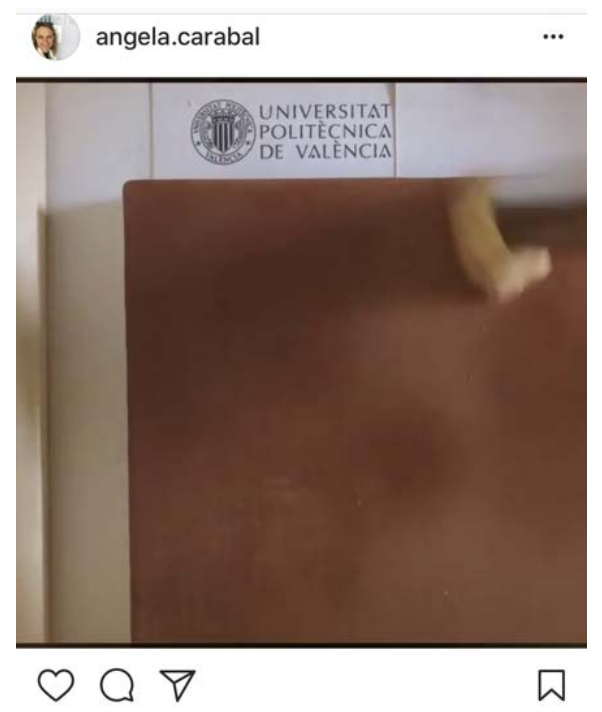

173 views $\cdot$ Liked by andreaacantos and aira_restaura

angela.carabal Preparando la superficie \#embolada con una lija fina o un pincel de cerda gruesa \#perrillo para que cerrar algo el poro y quede sin residuos para recibir la

\#coladepescado \#fishglue y el \#pandeoro \#goldleaf \#flippedteaching \#docenciainversa \#upv

Fig. 2. Vídeo de flipped teaching en la plataforma Instagram, con uno de los procesos de la práctica, previo a su ejecución en el aula.

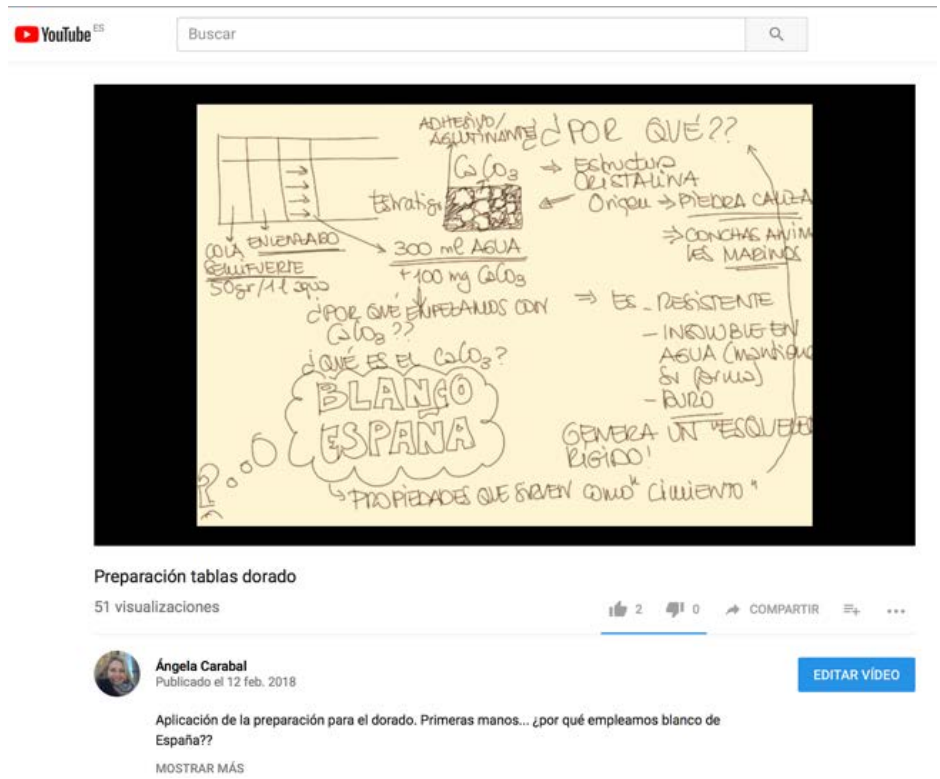

Fig. 3. Vídeo de flipped teaching en la plataforma Youtube, con la exposición de los materiales de uno de los procesos de la práctica, previo a su ejecución en el aula.

(cc) EY-Nc-No 2018, Universitat Politècnica de València 
María-Ángeles Carabal-Montagud, Virginia Santamarina-Campos, María-Victoria Esgueva-López, María de-Miguel-Molina

Cabe destacar que a través de la información enviada, se tiene constancia de los usuarios que han accedido a la información, o bien mediante la interacción directa con la imagen, o bien mediante el uso de una de las herramientas de la aplicación, consistentes en visualizar los usuarios que han accedido a la reproducción de los vídeos. Instantáneamente se reciben notificaciones con en número de reproducciones, en tiempo real, y los usuarios que lo han visualizado. En la figura 2 se puede observar el número de vistas y de interacciones.

También está la posibilidad de almacenar la información mediante una herramienta de archivo, que permite únicamente publicar durante el tiempo que se considere adecuado, resguardando los contenidos para emplearlos o bien en cursos posteriores o bien para tener una base y sustituirlos por otros, que se consideren más apropiados en posteriores cursos académicos. De este modo se va generando un repositorio, que el profesor puede utilizar, dependiendo de las necesidades de cada parte del temario o de la práctica.

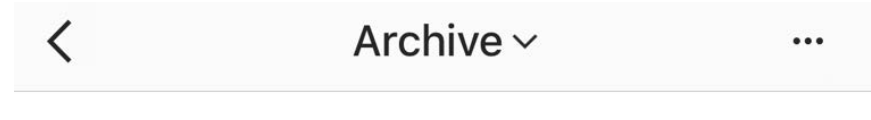

Only you can see the posts you've archived

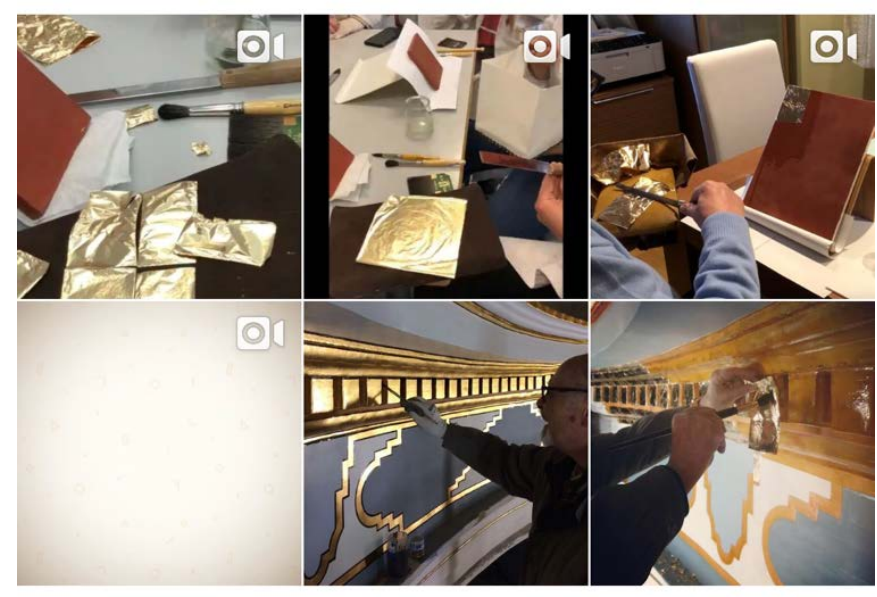

Fig. 4. Imágenes y vídeos de flipped teaching, archivados para cursos posteriores, una vez ya han cumplido su objetivo en el tiempo estipulado.

\subsubsection{Realizar una búsqueda de contenidos, seleccionar el material docente y compartirlo con el alumnado}

Con ello, se han ido subiendo imágenes y vídeos relacionados con la práctica durante el avance de la asignatura. Pero paralelamente, también se ha procedido a la búsqueda y selección de materiales generados y publicados por otros usuarios de dichas redes sociales y se han intercalado dependiendo de los contenidos de la asignatura.

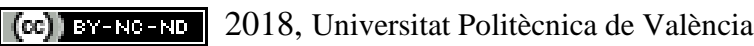

Congreso In-Red (2018) 


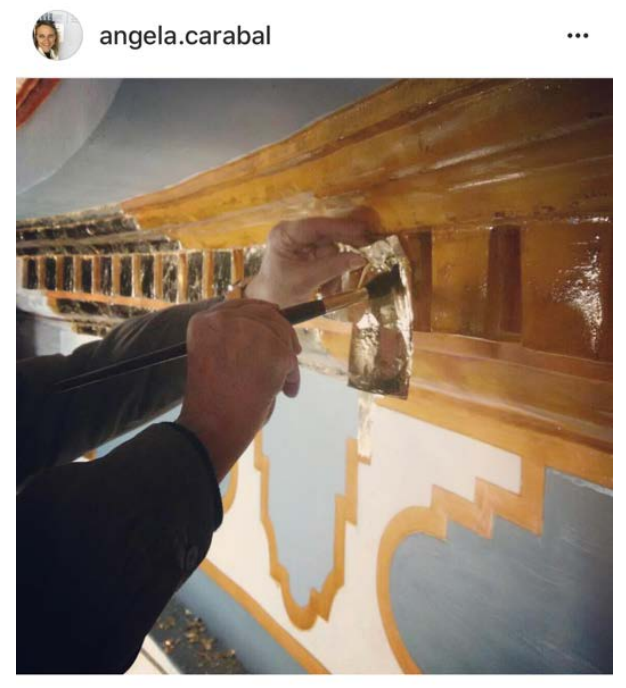

00

Liked by elisamartisa, art_conservation_studio and 69 others

angela.carabal \#procesos \#aplicación de los \#panesdeoro Foto que me envían directa desde la \#iglesia de \#banyeresdemariola \#gilding \#goldensurfaces \#flippedteaching angela.carabal

Universitat Politècnica de València UPV

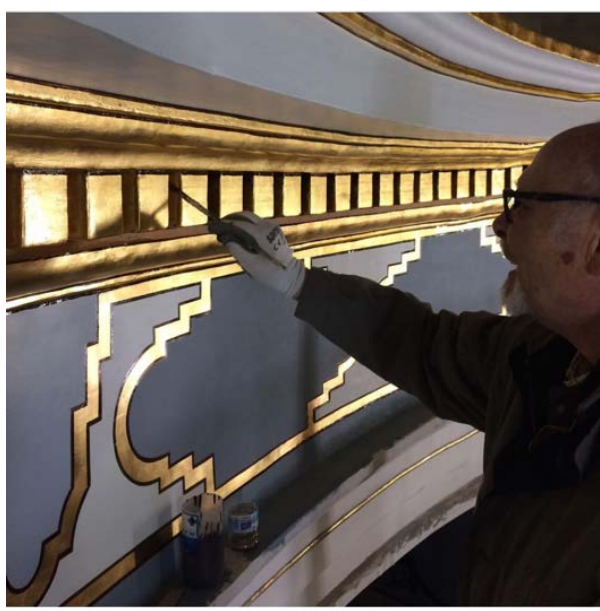

$\mathrm{OO}$

Liked by elisamartisa, andreaacantos and 53 others

angela.carabal Me envían el último proceso de \#dorado Observadlo y reforzamos contenidos en clase \#doradoypolicromía \#procesodorado \#flippedteaching \#gilding \#gildengsurfaces

Figs. 5,6. Imágenes de flipped teaching en la plataforma Instagram, con uno de los procesos de la práctica efectuado en empresas, previo a su ejecución en el aula.

La posibilidad que ofertan de compartir, facilita la tarea de puesta a disposición de la información al alumnado. En algunas ocasiones se ha compartido a través de dichas plataformas los enlaces, o directamente las imágenes y vídeos, pero en el caso de YouTube se ha procedido al empleo de PoliformaT para compartir la información del enlace URL para que los alumnos pudieran acceder. Este procedimiento responde al principal objetivo del presente estudio, que pretende sumar las plataformas activas institucionales junto con la redes sociales, de manera colaborativa.

En el caso de la citada asignatura, se ha realizado una compilación de todo el material que hay en la red, teniendo en cuenta que es cambiante y que cada día aparecen más recursos, lo cual genera en el alumno una visión de inmediatez, de actualidad, que suma valor la docencia inversa. Para ello, en Instagram, se han buscado imágenes de prácticas efectuadas o bien en empresas o bien en otro tipo de usuarios, realizando tareas como el dorado, la preparación de las tablas, el bruñido y el estofado, entre otros procesos. Al ser una 
María-Ángeles Carabal-Montagud, Virginia Santamarina-Campos, María-Victoria Esgueva-López, María de-Miguel-Molina

información pública, en ocasiones se ha compartido, o en otras ocasiones, se ha dado la referencia para que ellos acudan a la fuente de información.

También se han compartido imágenes de procesos previos, como el procesado del oro o como las diferentes aleaciones metálicas del pan de oro o plata, que pueden encontrar en el mercado, a través de búsqueda de empresas que utilicen la redes sociales y se dedican a la fabricación del oro, por poner un ejemplo.

De este modo, en este caso no solamente se utiliza para la consecución de las prácticas, sino también para entender de una manera visual la teoría y ayudar a la consecución de las competencias requeridas en la asignatura.

\section{Resultados}

Los datos recopilados de la innovación docente se van a clasificar teniendo en cuenta los diversos ámbitos que abarca y teniendo en cuenta la opinión de los receptores de la innovación docente, analizando por porcentajes los resultados obtenidos de la encuesta realizada a través de la plataforma SurveyMonkey ${ }^{\circledR}$.

\subsection{Encuesta de opinión del alumnado}

Con la finalidad de analizar los resultados obtenidos hasta el momento, con el empleo de las redes sociales como plataformas paralelas a las institucionales, se ha propuesto una encuesta en la citada plataforma, con contenidos que serán representativos para valorar la opinión de los destinatarios de la innovación. La encuesta consta de siete preguntas, acerca del flipped classroom en general y del uso de las redes sociales en particular.

\subsubsection{Valoración del uso de flipped classroom}

El 97,50\% del alumnado ha valorado como positiva la implantación, en términos de utilidad, de la docencia inversa para entender las prácticas y así agilizar su consecución. Con ello se corrobora que el alumnado entiende la implantación progresica de esta innovación metodológica. 


\section{Me resulta útil tener la información de modo previo a la} práctica a efectuar

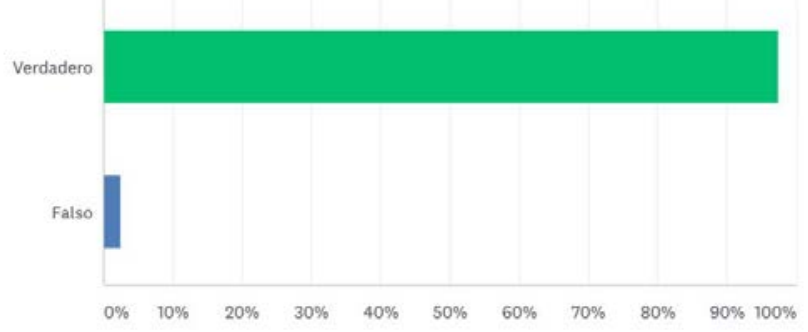

Fig. 7. Resultados de la encuesta con la plataforma SurveyMonkey®

Este porcentaje de respuesta resulta algo diferente cuando se pregunta acerca de la conveniencia de implantación de la docencia inversa en todas las asignaturas. La respuesta es afirmativa en el 77,50\% de los encuestados, mientas que el 22,50\% no valoran de modo positivo el flipped teaching para todas las asignaturas. Nuestra hipótesis al respecto es que, aunque sea de modo lúdico, ven incrementar con esta herramienta docente, el tiempo de dedicación no presencial.

\section{Creo que la docencia inversa (ver en casa cosas que nos hace ganar tiempo en clase) debería implantarse en todas las asignaturas}

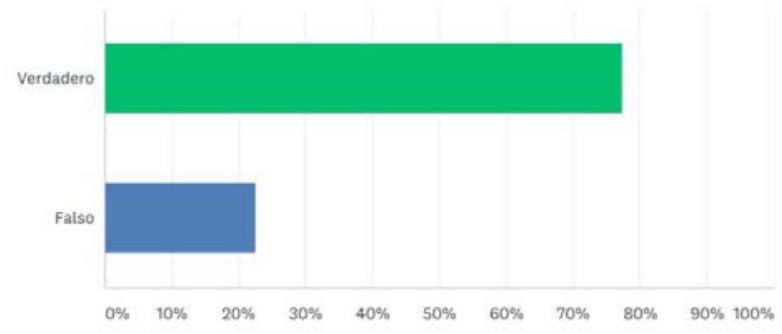

Fig. 8. Resultados de la encuesta con la plataforma SurveyMonkey®

Con todo, atendiendo a los porcentajes, es obvio que la docencia inversa es percibida por el alumnado como una herramienta útil, que ayuda a ganar tiempo en el aula.

\subsubsection{Valoración del uso de redes sociales para docencia inversa}

En general, la valoración del alumnado del uso de redes sociales y de sus preferencias de canales, también ha sido analizada en la presente investigación.

(cc)) EY-NC-ND 2018, Universitat Politècnica de València

Congreso IN-RED (2018) 
María-Ángeles Carabal-Montagud, Virginia Santamarina-Campos, María-Victoria Esgueva-López, María de-Miguel-Molina

Podemos concluir que en un $92,50 \%$ se valora de modo positivo el uso de redes sociales para la docencia inversa (Fig.9). A la hora de responder qué canales son más cómodos para ellos (Fig.10), para acceder a la información, un 40\% prefiere complementar los canales institucionales con las redes sociales, mientras que el 22,50\% prefiere el uso único de PoliformaT, y un 35\% refiere que le resulta indiferente uno u otro canal complementario. Un 2,5\% prefiere el uso de correo electrónico.

Al sondear al alumnado acerca del resultado obtenido, reseñan que para acceder a las plataformas institucionales el alumno tiene que insertar sus claves y suele hacerlo, en mayor medida, a través de tabletas u ordenadores, con lo cual, complementarlo con el uso de las redes sociales les da una visión más familiar y asequible de las tareas, dado que éstas responden mediante la entrada en una app, siendo más rápido y en un solo click.

La redes sociales me parecen un buen canal para comunicar con el alumnado

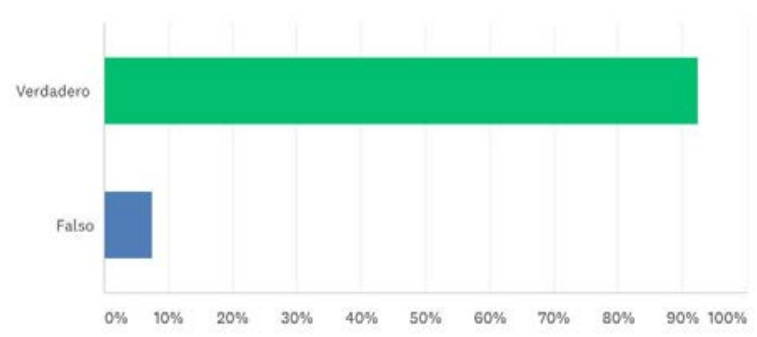

¿Qué canales son más cómodos para mi a la hora de acceder a la información?

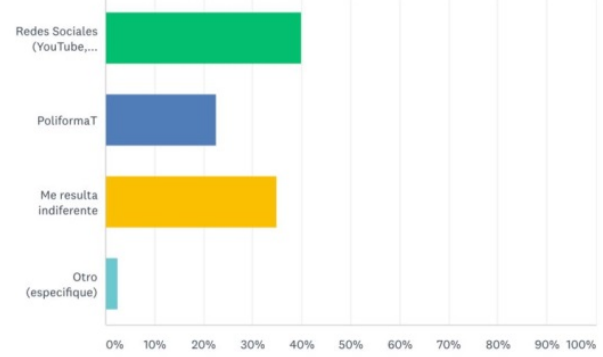

Figs. 9,10. Resultados de la encuesta con la plataforma SurveyMonkey®

Asimismo, cuando se les pregunta acerca de la percepción lúdica que añade el uso de redes sociales a la docencia inversa, un 90\% del alumnado opina de modo afirmativo (Fig.11). Con lo cual, el resultado principal de esta implementación se está cumpliendo de manera positiva.
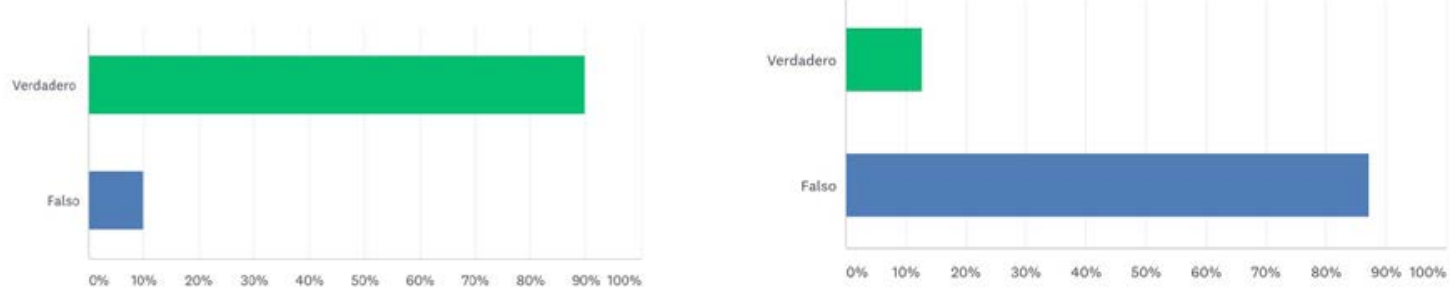

Figs. 11, 12. Resultados de la encuesta con la plataforma SurveyMonkey®

(c) ) EY-Nc-No 2018, Universitat Politècnica de València

Congreso In-Red (2018) 
No obstante, mientras se ha efectuado esta innovación docente se ha tenido en cuenta, como se ha citado con anterioridad, que el alumnado no sienta que los contenidos educativos invadan su parcela personal. Para averiguar si les produce cierta incomodidad el encontrar materiales docentes en sus redes, se les ha preguntado su percepción al respecto. Un 87,18\% niega que le resulte incómodo la implementación de la docencia inversa en las redes.

\subsection{Desarrollo y resultado de las prácticas}

Se ha observado una mejora en la planificación de las actividades prácticas, una mayor predisposición, por la seguridad que otorga el saber a qué se van a enfrentar, además de una mayor participación, un nivel cognitivo superior de la práctica, que se traduce en que cada vez presentan dudas más técnicas y complejas, además de suplirse problemas cotidianos relacuionados por el desconocimiento previo de la metodología a llevar a cabo.

Los resultados a nivel práctico, han sido también positivos, teniendo en cuenta que las consecuencias positivas obtenidas de la práctica han conllevado un aumento colaborativo y han favorecido la resolución de problemas, conducentes a un buen resultado final.

\section{Conclusiones}

En el presente estudio, fundamentalmente se analizan los resultados de la docencia inversa mediante dos vías: directamente en la consecución de las prácticas, en el modo de trabajar en el aula y en la mejora de los resultados. Al mismo tiempo se ha establecido otro tipo de valoración, mediante encuestas para validar la fiabilidad de los datos, a través de la correlación de los resultados.

El alumnado demanda una inmediatez, una fácil accesibilidad a la información mediante el uso de apps, un mayor uso de sus dispositivos móviles, que les otorgan la sensación de comodidad de acceso. Se trata de acercar la docencia a sus canales y códigos cotidianos, de modo que les resulte más asequible el acceder a los contenidos docentes.

Mediante el presente estudio se ha verificado que las redes sociales son bien valoradas por el alumnado y pueden emplearse, como canal complementario, para la docencia inversa. Refuerzan no sólo contenidos prácticos del aula, sino que también sirven para exponer la teoría, extrapolando la tarea o lo aprendido en el aula con la realidad empresarial fuera de la universidad, a modo de baño de realidad. De este modo se enlazan los contenidos de la asignatura con su futuro laboral, cumpliéndose uno de los objetivos más importantes de la presente metodología.

Otra de las conclusiones del presente estudio es la interactividad y la inmediatez de las redes sociales. Respecto a la plataforma YouTube, cabe destacar que el acceso a vídeos

(cc) BY-Nc-ND 2018, Universitat Politècnica de València

Congreso IN-RED (2018) 
María-Ángeles Carabal-Montagud, Virginia Santamarina-Campos, María-Victoria Esgueva-López, María de-Miguel-Molina

relacionados, a otros contenidos subidos por otros usuarios, resulta de gran utilidad a los alumnos. En Instagram la información es inmediata en los dos sentidos, tanto para el alumnado que la consulta, como para el profesorado, dado que las visualizaciones van ascendiendo en un corto espacio temporal, así como las interacciones con los contenidos, generándose un espacio virtual colaborativo.

Si bien es cierto que el uso de audiovisuales resulta muy útil en nuestra área, dada la carga visual que conlleva, cada uno tendría que valorar la implantación en su ámbito.

Supone un esfuerzo para el profesor y mayor tiempo de trabajo, además de que en ocasiones el mismo material no es aprovechable, suponiendo una práctica de innovación constante, porque en las redes se valora la inmediatez, pero los resultados obtenidos apuntan a que los alumnos lo prefieren, al acercarse a su realidad cotidiana.

\section{Referencias}

CARABAL, M.A. (2018) Flipped Classroom, encuesta en la plataforma SurveyMonkey®

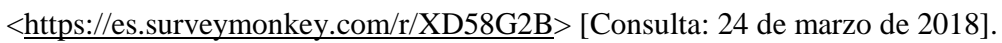

CARABAL MONTAGUD, MARÍA ÁNGELES (@angela.carabal). [Instagram]. $<$ www.instagram.com> [Consulta: 20 de marzoi de 2018].

CARABAL MONTAGUD, "Preparación tablas dorado". Youtube $<$ https://www.youtube.com/watch?v=wEZ-46TO4Cw > [Consulta: 23 de enero de 2018]

CARABAL-MONTAGUD, M.A., SANTAMARINA-CAMPOS, V., DE MIGUEL-MOLINA, M., DE MIGUEL-MOLINA, M.B., (2017). “Uso del Phubbing como estrategia de aprendizaje” UPV. En Comunica2. Valencia: Editorial UPV. Pp 107-121. ISBN 978-84-945855-3-1. Disponible en $<$ https://datos.comunica2.webs.upv.es/uploads/2018/02/Actas-7Comunica2-2017.pdf> [Consulta: 3 de marzo de 2018]

CIS. Participación en diferentes redes sociales durante los últimos tres meses. Barómetro de Noviembre de 2017. <http://www.analisis.cis.es/cisdb.jsp> [Consulta: 2 de febrero de 2018].

ESPINOSA MOLINA, M.A., CALCUCH-LOSA, A., SERRANO-COBOS, J. (2017). "Patrones de contenidos sociales en youtubers de moda española” UPV. En Comunica2. Valencia: Editorial UPV. Pp 133-148. ISBN 978-84-945855-3-1. Disponible en $<$ https://datos.comunica2.webs.upv.es/uploads/2018/02/Actas-7Comunica2-2017.pdf> [Consulta: 3 de marzo de 2018]

HARO, J.J., (2009). Las redes sociales aplicadas a la práctica docente. Spain: DIM. Didáctica, Innovación y Multimedia

< http://www.raco.cat/index.php/DIM/article/view/138928/189972 > [Consulta: 15 de enero de 2018].

(c)) EY-NC-ND 2018, Universitat Politècnica de València

Congreso In-Red (2018) 
TERRASA BARRENA, S., ANDREU GARCÍA, G. (2015) Cambio a metodología de clase inversa en una asignatura obligatoria.Actas del simposio-taller sobre estrategias y herramientas para el aprendizaje y la evaluación. Andorra La Vella. Pp.32-37. Disponible en <http://bioinfo.uib.es/ joemiro/aenui/procJenui/Jen2015/Tte_camb.pdf> [Consulta: 14 de marzo de 2018]

UPV. Página web de la Universitat Politècnica de València <www.upv.es> [Consulta: 23 de marzo de 2018]. 